\title{
Interleukin 1 Excretion Rate
}

National Cancer Institute

\section{Source}

National Cancer Institute. Interleukin 1 Excretion Rate. NCI Thesaurus. Code C156518.

The determination of the amount of interleukin 1 being excreted in a biological specimen over a defined period of time. 